\title{
Comments on: When neuroscience gets wet and hardcore: neurocognitive markers obtained during whole body water immersion
}

\author{
Xavier C. E. Vrijdag ${ }^{1}$
}

Received: 1 August 2017 / Accepted: 24 August 2017 / Published online: 30 August 2017

(C) Springer-Verlag GmbH Germany 2017

Keywords Letter to the editor $\cdot$ Diving $\cdot$ EEG $\cdot$ Gas narcosis

I would like to congratulate Schneider et al. (2014) with their publication of the technological advance in recording EEG in the condition of full body water immersion. This will make it possible to record the EEG in various situations and help to understand the effects of diving on the brain and by that advance the field of neuroscience.

The authors speculate that the modulating effect on the N200 latency and amplitude might possibly be due to an increase in intracranial pressure (ICP) caused by the increased environmental pressure experienced during water immersion. However, because there is a total submersion and there are no air cavities in the brain, there is no expectation of an increased ICP due to submersion. Our group did experiments on pigs where we measured the ICP during hyperbaric treatment to an equivalent of $18 \mathrm{~m}$ of seawater and we did not see a change in the ICP during this treatment (Weenink et al. 2013).

I would like to postulate another option for the reduction of the N200 latency and EEG frequency spectrum amplitude.
Gas narcosis in diving has been researched on numerous occasions and found to modulate the visual evoked potential and the EEG (Kinney et al. 1974; Pastena et al. 2005). Although Schneider et al. did their recordings at $5 \mathrm{~m}$ depth, gas narcosis might explain the non-significant changes in both measurement methods.

\section{References}

Kinney JA, Luria SM, Strauss MS (1974) Visual evoked responses and EEGs during shallow saturation diving. Aerosp Med 45(9):1017-1025

Pastena L, Faralli F, Mainardi G, Gagliardi R (2005) EEG patterns associated with nitrogen narcosis (breathing air at 9 ATA). Aviat Sp Environ Med 76(11):1031-1036

Schneider S, Cheung JJH, Frick H, Krehan S, Micke F, Sauer M et al (2014) When neuroscience gets wet and hardcore: neurocognitive markers obtained during whole body water immersion. Exp Brain Res 232(10):3325-3331. doi:10.1007/s00221-014-4019-5

Weenink RP, Hollmann MW, Vrijdag XCE, Van Lienden KP, De Boo DW, Stevens MF et al (2013) Hyperbaric oxygen does not improve cerebral function when started 2 or 4 hours after cerebral arterial gas embolism in swine. Crit Care Med 41(7):1719-1727
Xavier C. E. Vrijdag

x.vrijdag@gmail.com

1 Hyperbaric Medical Facility, Deep Dive Dubai, Dubai, United Arab Emirates 